At diagnosis, median ESR and CRP were $44 \mathrm{~mm} /$ hour [2-100] and $24 \mathrm{mg} / \mathrm{l}$ [2-86] respectively. Median JADAS10 score was 4 [0-21]. Median BASDAI score was $6.2[2-9.4]$

At follow-up, five patients (10.4\%) had atlantoaxial subluxation and 17 had coxitis (43.8\%).

At bone densitometry, $45 \%$ of patients had osteroposis and $27.5 \%$ had osteopenia.

An agreement was assessed between a long diagnosis delay and the following parameters: male gender $(p=0.04)$ and osteoporosis $(p=0.018)$. A Significant positive correlation was found between delay in JIA diagnosis and BASDAI score $(p=0.047, r=0.63)$. No association was found between JIA diagnosis delay and JADAS score $(p=0.56)$. Neither ESR $(p=0.19)$ nor CRP $(p=0.42)$ was associated with JIA diagnosis delay.

Finally, no link was observed with the occurrence of hip arthritis $(p=0.281)$ or atlantoaxial subluxation $(p=0.137)$.

Conclusion: In our study, the prevalence of AAI was $10.4 \%$. Prolonged corticosteroid use and elevated inflammatory markers were the major factors associated with an increased risk of upper cervical spine involvement. Hence, targeted treatments are required to prevent cervical spine instability.

REFERENCES:

[1] Hospach T, Maier J, Müller-Abt P, Patel A, Horneff G, von Kalle T. Cervical spine involvement in patients with juvenile idiopathic arthritis - MRI follow-up study. Pediatr Rheumatol Online J. 2014;12:9.

Disclosure of Interests: None declared

DOI: 10.1136/annrheumdis-2021-eular.3501

\section{AB0742 PREVALENCE AND RISK FACTORS OF OSTEOPOROSIS IN PATIENTS WITH JUVENILE IDIOPATHIC ARTHRITIS}

H. Bettaieb ${ }^{1}$, H. Ferjani ${ }^{1}$, K. Maatallah ${ }^{1}$, H. Boussaa ${ }^{1}$, D. Kaffel ${ }^{1}$, W. Hamdi ${ }^{1}$ ${ }^{1}$ Mohamed Kassab Institute of Orthopedics, Rheumatology, Tunis, Tunisia

Background: Childhood rheumatic diseases are associated with reduced Bone mass and increased risk of fractures (1). Several factors may interact to determine osteoporosis other than direct bone detrimental effects of the disease or its treatment.

Objectives: In this work, we aimed to investigate the prevalence of bone loss in patients with JIA and to determine the relative factors associated with osteoporosis during this chronic disease.

Methods: A retrospective monocentric study was carried out on JIA patients (ILAR criteria).Dual-energy $x$-ray absorptiometry (DEXA) was used to determine bone status. Disease activity was evaluated by JADAS10 (Juvenile Arthritis Disease Activity Score) in poly and oligoarticular subtypes and by BASDAI (Bath Ankylosing Spondylitis Disease Activity Index) in arthritis related enthesitis form. Erythrocyte sedimentation rate (ESR) and C-reactive protein (CRP) were noted The data were analyzed using the SPSS statistical package. A p value $<0.05$ was considered significant.

Results: The sample included 40 JIA (25 male and 15 female) with a mean age at disease onset of $11.3 \pm 3.6$ years. The median disease duration was 90 months [7-408]. The median JIA diagnosis delay was 8 months [1-108]. The JIA subgroups were in decreasing order of frequency: Enthesitis-related Arthritis $(n=27)$, Polyarticular RF- $(n=4)$, Polyarticular RF+ $(n=1)$, Oligoarticular $(n=4)$, Systemic $(n=2)$, Psoriatic Arthritis $(n=1)$ and Undifferentiated $(n=1)$. Median ESR and CRP were $29 \mathrm{~mm} /$ hour [2-98] and $14.5 \mathrm{mg} / \mathrm{l}$ [0-70] respectively. Median BASDAI score was 4.3 [1-9.7]. Median JADAS10 score was 1[1-21].

Overall, $45 \%$ of patients had osteoporosis, $27.5 \%$ had osteopenia, and $27.5 \%$ had normal bone densitometry. None of the patients had a history of vertebral or peripheral fractures.

Thirty per cent of patients $(n=12)$ were on long term corticosteroid therapy with a mean dose of $6.6 \pm 2.8 \mathrm{mg} /$ day. Only $12.5 \%(n=5)$ of them had a regular physical activity.

Osteoporosis was associated with age at JIA onset $(p=0.005)$, disease duration $(p=0.001)$, ESR $(p=0.08)$, CRP $(p=0.04)$, BASDAI score $(p=0.017)$ and sedentarily $(p=0.026)$. Osteopenia was only associated with corticosteroid therapy $(p=0.01)$. Neither osteoporosis $(p=0.37)$ nor Osteopenia $(p=0.25)$ was associated with disease activity score.

Conclusion: In our study, osteoporosis was a common feature during JIA. A long term corticosteroid therapy and sedentarily seem to be correlated with more impaired bone abnormalities. Hence, targeted interventions are urgently required to preserve bone health during JIA.

REFERENCES:

[1] McDonagh JE. Osteoporosis in juvenile idiopathic arthritis. Curr Opin Rheumatol. 2001;13(5):399-404.
Disclosure of Interests: None declared

DOI: 10.1136/annrheumdis-2021-eular.3522

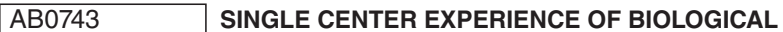 THERAPY IN PATIENTS WITH JUVENILE SYSTEMIC SCLERODERMA}

D. Alexseev ${ }^{1}$, I. Nikishina ${ }^{1}$, L. Ananieva ${ }^{1} .{ }^{1}$ V.A. Nasonova Research Institute of Rheumatology, Pediatric, Moscow, Russian Federation

Background: Juvenile systemic scleroderma (jSSC) is a rare multisystem disease with a poor prognosis. The current therapy is imperfect. Biologics, as a modern efficient option for treatment of rheumatic diseases don't have officia indication for jSSC, but it seems to be useful in severe cases, especially lung and heart damage.

Objectives: To analyze the existing experience of Biologics therapy in children with jSSC in single center in order to improve the understanding of the indications for use and the results of using these drugs.

Methods: The retrospective study include 9 patients with jSSC with severe course of disease, 7 of them were girls.

Results: Among this group of patients the age at disease onset was 9.1 years (min-max 1.1-15.1). Clinical manifestations: Raynaud's syndrome $(n=9)$, ulcers $(n=3)$, skin changes $(n=9)$, joints $(n=8)$, muscles $(n=4)$, interstitial lungs disease $(n=6)$, heart $(n=3)$, esophagus $(n=5)$, calcification $(n=3)$. The main therapy prior to the use of biological agents: glucocorticoids (GC) ( $\mathrm{n}=$ $9)$, cyclophosphamide (CF) $(n=2)$, hydroxychloroquine $(H C)(n=5)$, therapy for the microcirculation improvement. Biologics were prescribed in the case of insufficient effectiveness of previously conducted therapy, primarily in relation to lung damage (interstitial disease) and heart (with reduced contractility, arrhythmia), as well as changes in the skin and musculoskeletal system. In addition, the possibility to reduce the dose of $\mathrm{GC}(n=6)$, withdrawal of CF $(n=2)$ was taken into account. Our experience consist of follows: rituximab (RTM) $(n=7)$ at a dose of $375 \mathrm{mg} / \mathrm{m} 2$ interval 3-6 months, abatacept i.v.(ABT) $(\mathrm{n}=2) 10 \mathrm{mg} / \mathrm{kg}$ every 4 weeks, tocilizumab i.v.(TCZ) $(\mathrm{n}=2) 8 \mathrm{mg} / \mathrm{kg}$. In all cases Biologics was prescribed not earlier than 1.5 year after disease onset (4.6 years in average). By presen most patients continued to use biological therapy; of them - RTM was used for $2.2(0.5-6.0)$ years, in 1 patient - was canceled after 6 years due to the loss of efficasy; ABT is used in 2 children for 0.5 and 3.6 years, TCZ - in 2 children for 0.3 (withdrawal) and 2.0 years (continues to use)., TCZ was prescribed in 1 patient after 6 years of RTM use. In 1 patient TCZ was withdrawal due to an infusion reaction, and ABT was prescribed. As a result of the therapy, it has been found to improve habitus, quality of life and well-being, reduce skin tightening improve joint function; no progression of changes in the lungs according to CT and functional tests (FVC, DLCO), improvement in cardiac lesions. It seems that disease improvement became notable at least 3-6 months after the Biologics start. In most patients there were no serious adverse events (AE). No significan infections have been reported. But we met an unexpected case of substantia increasing of neutrophil's count just after each TCZ infusions up to 21,000 and reversed by following infusions for a one year of treatment from 2 years of total duration of using.

Conclusion: Our data shown that Biologics could be efficient and well-tolerated option for severe and resistant to "traditional» therapy course of jSSC Because this kind of condition is extremely rare further multicenter study is needed.

Disclosure of Interests: None declared

DOI: 10.1136/annrheumdis-2021-eular.3558

\section{$\mathrm{AB} 0744$ \\ HOW JUVENILE IDIOPATHIC ARTHRITIS PATIENTS PERCEIVE THEIR ILLNESS?}

K. Maatallah ${ }^{1}$, M. Yasmine ${ }^{1}$, H. Ferjani ${ }^{1}$, W. Triki ${ }^{1}$, D. Ben Ncib ${ }^{1}$, D. Kaffel ${ }^{1}$, W. Hamdi ${ }^{1}{ }^{1}$ Kassab Institute of Orthopedics, Rheumatology, Tunis, Tunisia

Background: Juvenile idiopathic arthritis (JIA) represents the most common inflammatory rheumatism of childhood. Because of a prolonged course of active disease, many patients experience physical and psychosocial limitations. Illness perceptions involve the personal beliefs that patients have about their illness and may influence health behaviors considerably.

Objectives: The present study aimed to investigate the illness perception of patients with JIA

Methods: We conducted a cross-sectional study including children with JIA (according to the International League of Associations for Rheumatology (ILAR)) We recorded sociodemographic data and the subtype of the JIA. To assess a child's perception of how arthritis affects their life, the Brief Illness Perception Questionnaire (IPQ) was completed by the parent (child age $\leq 10$ years) or by 
the child (age $\geq 11$ years). The Brief IPQ is a nine-item questionnaire rated using a 0-to10 response scale that assesses cognitive illness representations: consequences (Item 1), timeline (Item 2), personal control (Item 3), treatment control (Item 4), and identity (Item 5). Two of the items assess emotional representations: concern (Item 6) and emotions (Item 8). One item assesses illness comprehensibility (Item 7).

Results: The study included 22 patients. The mean age was $15 \pm 7$ years [4-35], and the mean age at diagnosis was $9 \pm 3$ years [3-14]. There was a female predominance (sex ratio $=2.1$ ). The frequency of each JIA subset was at follows: polyarticular with rheumatoid factor $(n=1)$, polyarticular without rheumatoid factor $(n=3)$, systemic $(n=2)$, enthesitis-related arthritis $(n=9)$, oligoarthritis $(n=7)$, undifferentiated $(n=1)$. Non-steroidal anti-inflammatory drugs were prescribed in $72 \%$ of cases, and Cs-DMARDs in $59 \%$ of patients. The most-reported causal factor in their illness was a history of traumatism (22\%). Perceiving symptoms (identity) were significantly related to being affected by the disease (emotional response) $(p=0.01)$. Conversely, patients who had personal and treatment control expressed less emotional response $(r=-0.7$, $r=-0.2$ respectively). Moreover, those who were concerned about the disease perceived more the consequences of their illness $(p=0.09)$ and understood it more $(p=0.029)$. We also noted significant correlations between personal control and treatment control $(p=0.033)$. A positive correlation was found between identity as well as consequences and timeline $(p=0.011, p=0.024)$, showing that the perception of chronicity was associated with pain and the burden of the disease.

Conclusion: Our study highlighted the importance of assessing illness perception in JIA patients. Patient education programs should be implemented since diagnosis for better disease management.

Disclosure of Interests: None declared

DOI: 10.1136/annrheumdis-2021-eular.3616

\section{AB0745 $\quad$ BONE STATUS IN CHILDREN WITH JUVENILE IDIOPATHIC ARTHRITIS (JIA) ON T2T THERAPY}

N. Shevchenko ${ }^{1,2}$, Y. Khadzhynova ${ }^{1,2}$, L. Bohmat ${ }^{1,2} .{ }^{1}$ V.N. Karazin Kharkiv National University, Department of Pediatrics No 2, Kharkiv, Ukraine; ${ }^{2} \mathrm{SI}$ Institute for Children and Adolescents Health Care of NAMS of Ukraine, Department of Cardiorheumatology, Kharkiv, Ukraine

Background: In recent years approaches to both the diagnosis and treatment of JIA have changed. Among it key positions for bone health are reducing the time to make a diagnosis and initiation of basic therapy, as well as reducing the timing and doses of corticosteroids. The interdependence of osteopenia in children with JIA with established impairment of vitamin D status, the prevalence of which remains very high in this cohort of patients, has also not been definitively elucidated.

Objectives: To study the condition of bone tissue in children with JIA in modern disease management and to identify adverse factors for the development of osteopenia among the clinical manifestations signs.

Methods: The study included 35 children with JIA aged 7 to 17 years, mostly female $(77.1 \%)$, with oligo - $(25.7) \%$, poly - $(60.0 \%)$ and undifferentiated $(14.3$ $\%$ ) arthritis, $53.4 \%$ have not yet received basic therapy. No corticosteroid therapy was available. The study of bone tissue was performed by two-energy X-ray absorptiometry (Explorer QD W-Hologic). All patients were tested for serum parathyroid hormone (PTH), the level of 25-hydroxyvitamin $\mathrm{D}[25(\mathrm{OH})$ $\mathrm{D}]$, the total and ionized calcium and blood phosphorus. The control group consisted of 12 healthy children of the same age with a normal level of 25 $(\mathrm{OH}) \mathrm{D}$.

Results: The average level of $25(\mathrm{OH}) \mathrm{D}$ was $20.41 \pm 1.35 \mathrm{ng} / \mathrm{ml}$, which is considered insufficient and was lower than in the control group $(30.03 \pm 2.53 \mathrm{ng} / \mathrm{ml}$, $\mathrm{p}<0.05)$. Studies of calcium and phosphorus in the blood showed that children with JIA have no deviations from the normative values. The majority of examined patients $(98.37 \%$ ) had normal values of $\mathrm{PTH}$, in average was $30.43 \pm 0.90 \mathrm{pg} / \mathrm{ml}$. The PTH was significantly different in children with different variants of JIA, the highest content was recorded in non-differential arthritis $(34.33 \pm 1.80 \mathrm{pg} / \mathrm{ml})$, the lowest - in the oligoarticular variant $(28.36 \pm 1.43, \mathrm{p}<0,05)$. PTH had a negative correlation with $25(\mathrm{OH}) \mathrm{D}$ status $(r=-0.41 ; p<0.05)$ and did not depend on the sex and disease activity.

The incidence of osteopenia was $28.57 \%$, its prevalence was almost the same in different variants of arthritis and did not depend on the sex and age of patients, positivity for RF. Osteopenia was more common in ANA-positive than in ANA-negative variant $(46.15 \%$ vs. $18.18 \%$; $p<0.05)$. In $30.0 \%$ patients with osteopenia decreased BMD reached the values of osteoporosis (more than $2.5 \sigma$ ). This group consisted of girls with predominantly polyarticular and undifferentiated JIA, with RF-negative and ANA-positive variant.

Deviations from the age normative values of BMD (Z-score) were associated with BMI $(r=0.33 ; p<0.05)$, JADAS scale results $(r=0.35 ; p<0.04)$, the number of active joints $(r=0.34 ; p<0.05)$, ANA ( $r=-0.34 ; p<0.05)$. In children with osteopenia it was correlated with the duration of the disease $(r=-0.67 ; p<0.05)$, the number of active joints $(r=-0.62 ; p<0.05)$, blood phosphorus level $(r=0.74 ; p<0.05)$ and JADAS scale results $(r=0.59 ; p<0.05)$. In children with preserved BMD correlations was supplemented by $25(\mathrm{OH}) \mathrm{D}$ status $(r=-0.33 ; p<0.05)$ and $\mathrm{BMI}(r=$ $0.40 ; p<0.05)$. Analysis of the interdependence of the formation of osteopenia and clinical manifestations signs established the total significance of the main parameters of the disease with the highest coefficient of determination in the polyarticular variant: $-112.65+0.09$ (patient's age, mo)+4.33 (patient's sex)3.74 (ANA, units)-1.80 (RF, units) +0.01 (age of onset, months)-0.34 (number of affected joints)-0.18 (number of active joints)-0.18 (ESR, mm/h) +71.58 (ionized calcium, mmol/l)+5.19 (phosphorus, mmol/l)-0.01 (PTH, ng/ml)+0.18 (25(OH)D, $\mathrm{ng} / \mathrm{ml})\left(\mathrm{R}^{2}=99.99 \% ; \mathrm{p}<0.001\right)$.

Conclusion: With modern JIA management a quarter of children have osteopenia. The state of the bone tissue is more associated with the prevalence, immunological and inflammatory activity of the disease against the background of preserved calcium-phosphorus homeostasis and vitamin D deficiency, and is not associated with the present therapy.

Disclosure of Interests: None declared

DOI: 10.1136/annrheumdis-2021-eular.3632

\section{\begin{tabular}{|l|l} 
AB0746 THE ASSOCIATION BETWEEN PRESARCOPENIA AND \\
B
\end{tabular} BONE MINERAL DENSITY IN ADULT PATIENTS WITH JUVENILE IDIOPATHIC ARTHRITIS}

M. Dzhus ${ }^{1}$, M. Kulyk ${ }^{1} .{ }^{1}$ Bogomolets National Medical University, Internal Medicine Department №2, Kyiv, Ukraine

Background: The importance of presarcopenia (low lean mass) in clinical practice is accompanied by a high risk of adverse effects such as early disability, reduced quality of life, and increased mortality.

Objectives: The aim of the study was to assess the link between bone mineral density (BMD) and the state of the muscular system in adult patients with juvenile idiopathic arthritis (JIA).

Methods: The study was performed in Oleksandrivska Clinical Hospital of Kyiv, Ukraine, where adult patients were transferred from pediatric rheumatologists. Inclusion criteria: patients aged 18-44 years at the time of signing the informed consent; diagnosis of JIA in childhood, verified according to ILAR criteria, duration of JIA $>3$ years. According to the European Working Group on Sarcopenia in the Elderly (EWGSOP) 2019, patients with a decrease in muscle mass alone were diagnosed with presarcopenia. The BMD and mus cle tissue were determined in standard localizations using dual X-ray absorptiometry (DXA).

Results: The study included 26 adult patients with JIA, including 10 male patients and 16 female patients. The mean age at the time of examination was $22.3 \pm 8.15$ years; the mean age at the onset of the disease was $9.04 \pm 4.9$ years. According to the ILAR classification, patients had the following variants of JIA: 3 patients with RF-negative polyarticular variant, 8 patients with persistent oligoarthritis, 4 patients with extended oligoarthritis, 6 patients with RF-positive polyarthritis variant, and 5 patients with systemic JIA. According to the EWG SOP, 2019 reduced muscle mass was calculated by skeletal muscle index (SMI); the cut-off points were considered by SMI $<7 \mathrm{~kg} / \mathrm{m} 2$ for male, $<6 \mathrm{~kg} / \mathrm{m} 2$ for female. Patients were divided into two groups depending on the presence or absence of presarcopenia. The first group (1-st group) included 16 patients with reduced muscle mass (SMI - 5,22 $0,72 \mathrm{~kg} / \mathrm{m} 2$ ), and the second group (2-nd group) included 10 patients without reduced muscle mass (SMI $-8,05 \pm 0,94 \mathrm{~kg} / \mathrm{m} 2$ ). It was found that the height and weight of patients in the group of presarcopenia was lower than in the group without a low lean mass (height $1,6 \pm 0,07$ $m$ vs $1,7 \pm 0,09 \mathrm{~m}, \mathrm{t}=-2,53 ; \mathrm{p}=0,01$; weight $55,06 \pm 8,3 \mathrm{~kg}, 70,0 \pm 10,8 \mathrm{~kg}, \mathrm{t}=-3,9$; $p=0,0007$, respectively). The age of patients $(25,3 \pm 10,1$ and $21,3 \pm 5,9$ years for 1-st and 2-nd groups respectively) and the duration of the disease (17,1 $\pm 9,5$ and 10,3 $\pm 6,1$ for 1 -st and 2-nd groups respectively) did not differ statistically between the groups. The age of the onset of JIA in both groups also did not differ (7,8 $\pm 4,5$ and $11,5 \pm 4,1$ for the 1 -st and 2-nd group respectively). The following data were obtained by DXA. The patients of 1-st group had statistically reduced $B M D$ in the region of femoral neck $-0,927 \pm 0,15 \mathrm{~g} / \mathrm{cm} 2$ vs $1,179 \pm 0,13 \mathrm{~g} /$ $\mathrm{cm} 2, \mathrm{t}=-3,18 ; \mathrm{p}=0,006$; total hip - $0,977 \pm 0,16 \mathrm{~g} / \mathrm{cm} 2$ vs $1,184 \pm 0,05 \mathrm{~g} / \mathrm{cm} 2$, $\mathrm{t}=-3,05, \mathrm{p}=0,0080$; total body $-1,080 \pm 0,1 \mathrm{~g} / \mathrm{cm} 2$ vs $1,193 \pm 0,15 \mathrm{~g} / \mathrm{cm} 2, \mathrm{t}=-2,19$ $\mathrm{p}=0,03$; and ultra-distal radius $-0,286 \pm 0,06 \mathrm{~g} / \mathrm{cm} 2$ vs $0,482 \pm 0,11 \mathrm{~g} / \mathrm{cm} 2, \mathrm{t}=-3,60$; $p=0,007$. The $B M D$ in the region of lumbar spine did not differ in two groups $-1,152 \pm 0,16 \mathrm{~g} / \mathrm{cm} 2$ vs $1,137 \pm 0,17 \mathrm{~g} / \mathrm{cm} 2, t=0,21 ; p=0,8$. In the group of presarcopenia there was a visible decrease in the level of the metabolite of vitamin $25(\mathrm{OH}) \mathrm{D} 3$, but not statistically significant: $15,5 \pm 7,3 \mathrm{nmol} / \mathrm{l}$ vs $19,7 \pm 8,6 \mathrm{nmol} / \mathrm{l}, \mathrm{t}$ $=1,0 ; p=0,3$. The study has strengths such as first described presarcopenia in young adults with JIA and potential limitations such as mono-center study and a small number of patients. 